\title{
Understanding Poverty Rate Dynamics in Moderately Poor Urban Neighborhoods: A Competitive Perspective
}

\author{
Chunhui Ren ${ }^{1 *}$, Hazel Morrow-Jones ${ }^{2}$ \\ ${ }^{1}$ University of Texas at Austin, Austin, USA \\ ${ }^{2}$ The Ohio State University, Columbus, USA \\ Email: ren.36@utexas.edu, Morrow-jones.1@osu.edu
}

Received November 23 ${ }^{\text {rd }}$, 2013; revised December 23 ${ }^{\text {rd }}$, 2013; accepted December $30^{\text {th }}$, 2013

\begin{abstract}
Copyright (c) 2014 Chunhui Ren, Hazel Morrow-Jones. This is an open access article distributed under the Creative Commons Attribution License, which permits unrestricted use, distribution, and reproduction in any medium, provided the original work is properly cited. In accordance of the Creative Commons Attribution License all Copyrights (C) 2014 are reserved for SCIRP and the owner of the intellectual property Chunhui Ren, Hazel Morrow-Jones. All Copyright (c) 2014 are guarded by law and by SCIRP as a guardian.
\end{abstract}

This study introduces a framework to model moderate-to-high poverty transition in urban neighborhoods using their relative competitive positions within metropolitan areas. Relative competitive position is measured by a variety of neighborhood attributes, including resident and neighborhood characteristics, locational attributes, among others. The model was estimated using the decennial census, using tracts from 1990 and 2000 as proxies for neighborhoods. Results indicate that the competitive model works well as a method to evaluate neighborhood poverty transition. Neighborhoods with relatively unfavorable competitive positions within a metropolitan area experience more poverty growth and therefore are likely to have more concentrated poverty in the future. Based on the results, several recommendations are made to intervene. These include promoting public transit, immigrant assimilation programs, among others.

Keywords: Housing; Community; Minority; Neighborhood; Poverty

\section{Introduction}

If the poor population were evenly distributed, poor individuals would only have to cope with their low incomes. But in reality, poor people tend to live near other poor people in neighborhoods with high poverty rates. The concentration of low-income people leads to many social problems, such as persistent unemployment, poor school performance, and welfare dependency. Therefore, poor individuals not only have to deal with their personal financial difficulties, but to "suffer from the negative effects brought about by the harsh social environment which is caused by poverty and is causing poverty as well" (Jargowsky, 2003). The deleterious consequences of highpoverty neighborhoods have been discussed and studied by many urban researchers and include, for example negative effects on property values, child development, and political activity (Cohen \& Dawson, 1993; Oreopoulos, 2003; Kingsley \& Petit, 2003).

Many urban researchers focus on how to improve the conditions of high-poverty neighborhoods to get them out of the high-poverty status (see for example, Fogarty, 1977; Wilson, 1987; Massey \& Eggers, 1990; Kasarda, 1993; Galster et al., 2003; Ellen \& O’Regan, 2007; Rosenthal, 2007). Relatively fewer studies have systematically modelled the process in which healthy neighborhoods decline into high-poverty areas.

The basic proposition of this study is that the best way to fight concentrated poverty is to discover the dynamics of lowerpoverty neighborhoods so that policy inventions can be made to

\footnotetext{
"Corresponding author.
}

impede the poverty concentration process. In this study, poverty dynamics in moderately poor urban neighborhoods are modeled from a competitive perspective. That is, we see neighborhood poverty change as a result of inter-neighborhood competition, as those neighborhoods with disadvantaged positions are more likely to experience further declines and fall into higher-poverty categories, while those with more favorable positions show stronger ability to resist further poverty concentration.

In this study, we introduce a competitive conceptual framework to explore poverty dynamics patterns in moderate-poverty neighborhoods in metropolitan America during the 1990s. We begin with a brief discussion of past literature on neighborhood poverty and then introduce the conceptual framework for the analysis. We offer a first test of the framework using data from the Neighborhood Change Database (NCDB) and OLS regression. We conclude with the major findings, their policy implications and an agenda for future research based on the model.

\section{Literature Review and the Competitive Model}

Most of the earlystudies on concentrated poverty are crosssectional. Their efforts were focused on different geographic areas varying in their levels of poverty (Massey, Eggers, \& Denton, 1990; Eggers \& Massey, 1992; Hughes, 1989; Mincy et al., 1990). More recently, urban scientists began to pay attention to the dynamic nature of neighborhood poverty issues and started to explore factors that are predictive of a neighborhood's future course of poverty transition. In general, they approach urban poverty dynamics from the following perspectives. 


\section{Job Market Competition}

Neighborhood poverty status is typically defined by the proportion of low-income population in the neighborhood. Therefore, the most intuitive mechanism for measuring poverty transition is through people's income level changes as a result of job market outcomes. Three groups of characteristics are found to affect neighborhood residents' earning potential. Some neighborhood resident characteristics affect people's competitive ability through straightforward market processes. These include age, educational attainments, work experiences, language barriers, and others (Massey \& Eggers, 1990; Kasarda, 1993; Galster \& Mincy, 1993). These factors give a neighborhood's residents advantages or disadvantages based on pure market mechanisms. Some other factors distort market rationality and put specific groups in disadvantaged positions and make their neighborhoods more vulnerable to increased poverty concentration, such as racial discrimination in labor markets. A neighborhood's geographical location is also an important factor in determining its residents' access to employment opportunities. These include, but not limited to, the distance to employment centers, the access to public transit (Galster \& Mincy, 1993).

\section{Housing Stock Filtering}

The basic tenet of filtering models is that as the housing stock of a neighborhood ages, more affluent households move out in search of more appealing residential options and their vacancies are often filled by less affluent in-movers. As this process continues, neighborhoods experience declines in their economic status (Metzger, 2000). According to this perspective, the age of a neighborhood's housing stock is the key to understanding its subsequent course of economic status change. Many urban researchers include in their models neighborhood age indicators to capture the effect of the filtering process (Brueckner, 1977; Galster et al., 2003; Rosenthal, 2007; Ellen \& O’Regan, 2007). But the empirical evidence is far from consistent. Based on data in the 1950s and 1960s, Brueckner (1977) found a positive correlation between a neighborhood's downward income succession and the proportion of old housing units. Recent evidence, however, suggests that old housing stock is not necessarily correlated with poverty growth, since as a neighborhood gets older, it is more likely to become the target for urban redevelopment, which will attract more affluent households and therefore elevate the neighborhood's economic status in future (Ellen \& O’Regan, 2007; Rosenthal, 2007).

\section{Social Externalities}

Another strand of theories to explain neighborhood poverty growth, as summarized by Rosenthal (2007), is based on neighborhood social externalities. This argument suggests that certain types of households tend to behave in ways that generate social capital or social costs for the neighborhood. These in turn play an essential role in affecting households' decisions about moving into or out of the neighborhood. For example, households with high educational attainments are expected to generate social capital, which attracts higher status residents and therefore enhance the neighborhood's future economic status. Low-income families serve as an opposite example. Therefore, age alone can't explain a neighborhood's subsequent courses of poverty transition, since the life-cycle stages are accelerated or delayed by the social capital and social costs associated with that neighborhood (Rosenthal, 2007).

\section{Expectation}

The change in neighborhood poverty status results from the decisions and activities of the actors involved in the neighborhood process. Those decisions and activities are mainly based on economic, racial and cultural considerations on the part of residents. The important question that arises is: do they make their decisions solely based on the current status of the neighborhood attributes? Early empirical studies usually take this as an assumption (Massey, Eggers, \& Denton, 1990; Mincy et al., 1990). As a consequence, their results are, to some degree, cross-sectional approximations of the dynamic process (Galster \& Mincy, 1993). But in reality, people's expectations play an essential role in determining decisions about residential location, financial investments, housing upkeep efforts, and others (Galster, 2001). More recently, increasing attention has been paid to the expectation side of neighborhood poverty transition processes. Ellen (2000) proposes a new hypothesis to explain neighborhood racial transition, which attributes the key driving force of racial transition to white people's racially-based predictions on future neighborhood quality. This explanation of racial transition can be easily applied to understand neighborhood poverty change as well. Rosenthal's (2007) model also takes the expectation factors into account with the housing age and externality theories. As the presence of social-capital related attributes reinforce people's positive expectation about future neighborhood quality, the consequent in-migration of more affluent households enhances the neighborhood's economic status. The presence of social-cost related attributes behaves in the opposite way.

\section{Threshold Effects}

Threshold effects are another non-negligible aspect of neighborhood poverty succession that urban researchers have long been aware of. Typically, as the level of one neighborhood attribute exceeds certain threshold values, the behavior of the actors in the neighborhood might change in an exponential way rather than a simple linear way. For example, as a neighborhood's negative attributes surpass certain critical values, they might lead to rapid poverty growth either by generating accelerated out-migration of non-poor residents or by causing rapid increases in negative behavior of the stayers. Crime and poor school quality are examples of typically perceived negative neighborhood attributes (Downs, 1994). Increases in the share of low-status residents and racial minorities are believed to have substantially contributed to "middle-class flight" in the 1960s. Similarly, as the level of a beneficial behavior exceeds certain threshold values, the subsequent positive changes may upgrade the neighborhood's economic status. For instance, the housing-upgrading behavior of a household depends, to a great extent, on the number or proportion of other households who choose to do so. Once this surpasses a certain critical level, more households will follow in pursuit of capital gains through increased neighborhood property value (Quercia \& Galster, 2000).

\section{A New Conceptual Framework}

The conceptual framework for the research is based on the 
literature cited above and focuses on a competitive perspective. It is assumed that neighborhood poverty dynamics are natural outcomes of inter-neighborhood competitions within the same region. The competition occurs in two ways. It can be either in the form of competing for employment opportunities on the part of neighborhood residents, or in the form of competing for more affluent households on the part of the neighborhoods themselves. Thus, according to this competitive perspective, the neighborhood poverty transition can be viewed as being caused by two processes. One is the incumbent income changes of the neighborhood residents, resulting from changes in employment outcomes. Another process is the migration of households with various levels of economic status.

Therefore, based on those two poverty change mechanisms, we propose the concepts of income-related competitive disadvantage/advantage and mobility-related competitive disadvantage/advantage to explain a neighborhood's subsequent course of poverty transition. Within a given region, the former is used to measure a neighborhood's competitive position in terms of its residents' ability to maintain and improve their earning potential. And the latter is used to assess a neighborhood's competitive position in terms of its locational attractiveness, or in other words, a neighborhood's ability to maintain and attract relatively higher status households.

The concept of income-related competitive disadvantage/ advantage can be understood within the framework of job market competition. People living in a neighborhood with a favorable competitive position as compared with other neighborhoods in the same region, are less likely to experience income decline, which therefore enhances the neighborhood's ability to resist negative poverty transition, and vice versa. Mobility-related competitive disadvantage/advantage, on the other hand, measures a neighborhood's relative attractiveness to more affluent households. Households make residential location decisions according to their evaluation of various neighborhood attributes. The evaluation, however, is not based on intrinsic characteristics of these attributes, but on a comparison of them in competing areas (Galster, 2001). In other words, what determines a neighborhood's attractiveness is not the absolute value of its attributes but its relative position in the large scale geographic region. Therefore, the relativistic evaluation leads to interneighborhood competition where neighborhoods are placed in different competitive positions according to their relative levels of competitive features.

The concept of mobility-related competitive disadvantage/ advantage is also closely related to the aforementioned expectation aspect of poverty transition. That is, neighborhood poverty change can be seen as a function of people's residential decisions based on their expectation about future neighborhood quality. As social externality theories suggest, some neighborhood characteristics such as dilapidated housing stock, high crime rates and other bad behaviors of the residents, weaken people's perceived prospect of the neighborhood and cause middle-class flight. While other characteristics such as high homeownership rates and the presence of a large proportion of highly educated residents, may reinforce people's confidence and therefore make the neighborhood more appealing to affluent households (DiPasquale \& Glaeser, 1999). The age and physical conditions of the housing stock function in a similar way. Newer housing stock is usually perceived to be associated with neighborhood upgrading which attracts households with relatively higher economic status, while older housing stock generally confirms people's negative expectation on future neighborhood quality and therefore causes neighborhood to decline. In addition, the factors on which the expectation is based may go beyond the current conditions and the geographical boundaries of the neighborhood. For example, the past pattern of racial composition change is found to be an important predictor of future neighborhood racial transition (Ellen, 2000). Income-transitions in adjacent areas also affect people's residential decisions as suggested by border models (Leven et al., 1976).

As Figure 1 illustrates, the theoretical framework of this study proposes that neighborhood poverty change can be accounted for by a neighborhood's relative competitive position measured by its characteristics in the light of income-related competitive disadvantage/advantage and mobility-related competitive disadvantage/advantage. It should be noted that the effects of those two types of characteristics are not completely exclusive of each other. That is, some income-related factors also contribute to poverty change by causing selective migration and vice versa. The grouping is primarily based on their expected major poverty-generating mechanisms as suggested by previous studies. As Figure 1 demonstrates, solid lines indicate major effects while dotted lines indicate minor effects. In the quantitative analysis, a set of explanatory variables, selected on the basis of the above concepts, will be tested as to their ability to explain poverty change.

\section{Data, Study Area, and Variables}

\section{Data}

The primary source of data used in this study is the Neighborhood Change Database (NCDB) developed by Geolytics in conjunction with the Urban Institute. It contains data from four decennial census years: 1970, 1980, 1990 and 2000. The unique feature of this data set is that the tract boundaries from all four census years are standardized based on their census 2000 locations. This feature provides convenience for longitudinal studies. Many empirical studies have been designed to take advantage of NCDB's longitudinal data structure. Ellen and O’Regan (2007) use NCDB to compare neighborhood economic status dynamic patterns across the three decades (1970-2000) and find that several unique patterns occurred in the 1990s, such as significant economic gains in the most impoverished neighborhoods. Kingsley and Petit (2003) use NCDB to examine the 1970-2000 trends of poverty concentration in US metropolitan areas. They also notice the flow of economic gains into high-poverty neighborhoods during the 1990s and point out that "the poverty reduction occurred as the net result of different types of neighborhoods moving in and out of the highpoverty category rather than the incumbent changes in highpoverty areas".

Although the NCDB has a great advantage for longitudinal studies, it also has limitations that users should be aware of (Tatian, 2003). First of all, since many tracts have changed boundaries over the four decennial census years, the forced standard boundaries are bound to lead to inaccurate information. Secondly, because of the changes in the way certain data are collected and tabulated, some variables are defined differently by different census years. Finally, to provide convenience for cross-decade comparison, the selection of variables for the NCDB emphasizes those variables available in all census years. 


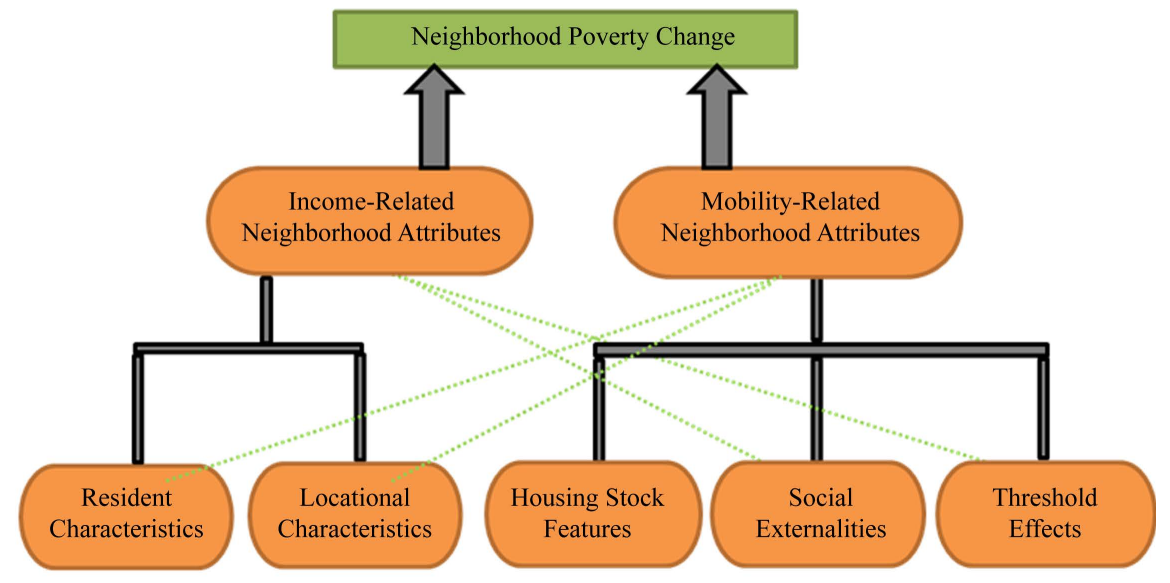

Figure 1.

The conceptual framework.

Therefore, some variables available only in certain census years are not included. Since our study only focuses on the 19902000 Period and use variables that were defined consistently in both of these two census years, we do not expect to see significant biases and inaccuracies.

REIS is the acronym for the Regional Economic Information System created by the Bureau of Economic Analysis (BEA) to make available employment information by detailed industrial file and at different geographic levels. In this study, all the employment-related variables are calculated based on REIS. ${ }^{1}$

\section{Study Areas}

This study is based in the 100 largest metropolitan areas at the time of the 1990 census as measured by the size of population. A metropolitan area typically has one or several population centers surrounded by suburban counties. The Census Bureau defines several types of metropolitan areas. There are stand-alone Metropolitan Statistical Areas, known as standard MSAs, Consolidated Metropolitan Statistical Areas (CMSAs) and Primary Metropolitan Statistical Areas (PMSAs). PMSAs are component units of CMSAs. The metropolitan areas defined in this study include both MSAs and PMSAs. CMSAs are excluded because they are too large to be representative of unified housing and labor markets (Jargowsky, 2003), and therefore can not ensure competitive relationship between component neighborhoods. Appendix A shows a list of the 100 largest MSAs and PMSAs by population size.

\section{Unit of Analysis}

Consistent with previous work (Fogarty, 1977; Galster \& Mincy, 1993; Galster et al., 2003; Kingsley \& Pettit, 2003; Jargowsky, 2003; Rosenthal, 2007; Ellen \& O’Regan, 2007), census tracts are used as proxies for urban neighborhoods. "census tracts are usually delineated by bounding features such as roads or rivers, and are supposed to have relatively homogeneous attributes with regard to economic, social and housing stock characteristics" (Jargowsky, 2003). Some urban scientists suggest that using block groups might be a better choice (Schuler

\footnotetext{
${ }^{1}$ There is an inconsistency with regard to MSA boundaries between REIS and NCDB. To deal with this problem, REIS MSAs are broken down into counties and reorganized to match the boundaries of NCDB.
}

et al., 1992). However many important socioeconomic variables are not available at the block group level. Also, using census tracts is consistent with most of the previous studies, making it easier to conduct historical comparison (Ellen, 2000). Therefore, although not perfect, census tracts are the best approximations to neighborhoods available for the quantitative analysis. The terms "neighborhood" and "census tract” are used interchangeably in the remainder of this paper.

\section{The Dependent Variable}

The poverty rate is defined by the US Census Bureau as a percentage of the residents living below the Census Bureau Poverty Line. That is, a person is considered poor if he or she lives in a family with an income less than the Census Bureau Poverty Standard which is meant to reflect the costs of buying life necessities in the area and adjusted for inflation and family size (Jargowsky, 2003).

There has been no academic consensus on what poverty rate cutoffs should be used to classify neighborhood into different categories. Scholars use varying cut off values, depending on specific emphases of the research. Jargowsky and Bane (1990), Kasarda (1993) and Jargowsky (1997), for example, used a $40 \%$ poverty rate as the threshold to distinguish "ghettos" from mixed-income neighborhoods and this cutoff is chosen primarily based on the experienced researchers' observations of physical appearance in the neighborhoods. Galster and colleagues (2003) used the $20 \%$ poverty rate as the cut off between moderate-poverty and high-poverty neighborhoods and the $40 \%$ poverty as the cut off between high-poverty and extremely high-poverty neighborhoods. Those cut off values are chosen because historical studies indicate exacerbated social problems once poverty rates exceed such threshold values (Galster et al., 2003).

In this study, we employ $10 \%$ and $20 \%$ poverty rates as the cutoff values to distinguish moderate-poverty neighborhoods from low-poverty and high-poverty neighborhoods ${ }^{2}$. If a census tract has between $10 \%$ and $20 \%$ residents living below the Census Bureau Poverty Level, it's classified as a moderate-

${ }^{2}$ Low-poverty, high-poverty and extremely high-poverty neighborhoods are defined as those with below $10 \%$ poverty rates, between $20 \%$ and $40 \%$ poverty rates, and above $40 \%$ poverty rates. Refer to appendix table B for descriptive statistics of these different poverty-level tracts. 
poverty neighborhood. The dependent variable in this study is defined as the absolute difference in neighborhood poverty rate between 1990 and 2000 .

\section{Explanatory Variables}

As discussed in the conceptual framework, this research intends to use a neighborhood's relative competitive position in the metropolitan area to explain the variation in future poverty rate change. Most prior work calculates a neighborhood's relative position in terms of a certain attribute by using a ratio of the value of the neighborhood to the average value of the MSA (Rosenthal, 2007; Ellen \& O’Regan, 2007). In this study, however, the measure of a neighborhood's position relative to the entire MSA holds less explanatory power, because neighborhoods in different economic status categories usually do not have a direct competitive relationship. Therefore, in this study, a neighborhood's relative competitive status in terms of a certain attribute is measured by using a ratio of the neighborhood value to the average value of all neighborhoods of the same poverty category in the MSA. For example, a moderate-poverty neighborhood's relative competitive position measured by homeownership rate is calculated by a ratio of the neighborhood homeownership rate to the average homeownership rate of all moderate-poverty neighborhoods in the MSA. All neighborhood-level variables used in this study are measured this way except for dummy variables. The purpose of this measurement is to ensure that neighborhoods within a metropolitan area form a direct competitive relationship with each other, which is the fundamental idea of this study.

Based on the conceptual framework and past empirical studies, a set of explanatory variables are selected to measure a neighborhood's relative competitive position within the MSA (See Table 1 for the detailed descriptions of the variables, and table B in the Appendix section for their descriptive statistics). In the model, the dependent variable is measured by decadal changes 1990-2000, and most explanatory variables are in beginning-of-period values while some of them are changes in the previous decade. The idea is that the beginning-of-period values of a neighborhood's attributes are predictive of its future course of poverty transition in the next decade. Dummy variables are added to test possible threshold effects of the selected neighborhood attributes.

\section{Discussion of Model Results}

Originally there are 17,986 NCBD census tracts that have a moderate poverty status. After excluding 10,172 inappropriate tracts, the reported results are based on 7814 moderate poverty census tracts in the 100 largest US metropolitan statistical areas. The excluded tracts include 1) those not located in the 100 largest MSAs (in rural areas or small MSAs); 2) those with 0 population or 0 poverty-status determined population in 1980 and 2000; 3) those with a population less than 100 in 1990; 4) those with 0 families in $1990 ; 5)$ those with $10 \%$ or more of their populations in mental hospital or juvenile institutions; 6) those with $40 \%$ or more of their populations in military institutions, college dormitories, other institutions and non-institutional quarters.

\section{Overview}

Table 2 shows model results based on the Ordinary Least
Square regression (OLS). The R-squared statistic is 0.202 , which is a typically low value for models predicting neighborhood poverty change. Almost all the estimated coefficients are significant with the expected signs. This is very rare compared with previous studies, indicating that using a neighborhood's relative competitive position to predict its future course of poverty transition generally works well.

\section{Income-Related Neighborhood Attributes}

Consistent with historical findings (Scott, 1988; Galster \& Mincy, 1993), low educational attainment in a neighborhood is found to be a negative characteristic that puts the neighborhood's residents in an unfavorable position in employment markets. One possible explanation for the positive coefficient on Foreign90 is that new immigrants still suffer from a language barrier and the lack of middle-class social connection. Although some prior studies suggest that there might be positive effects due to their support network based on homogeneous backgrounds, such effects are found to be minor in moderately poor areas. A relatively higher proportion of female-headed families also makes the neighborhood more likely to experience poverty growth. It is not possible to tell with the available data if this affects poverty rate change through welfare dependency or by giving women additional difficulty in job market competition or in some other manner. The variable NoCar90 is used to test the effect of automobile ownership on people's competitive position in employment markets. As it turns out, in moderate-poverty neighborhoods, the relative lack of transportation means significantly limits people's access to job opportunities (Galster \& Mincy, 1993). Finally, a neighborhood that has a relatively larger portion of married-couple families is less likely go through poverty growth, which indicates marriage's positive role in resisting economic hardship, be it financially or psychologically.

Two variables are included to test a neighborhood's locational disadvantages or advantages in its residents' access to employment opportunities. Both Access-To-Local-Job90 and Distance-To-CBD90 turn out to be significant, but the influence of the distance to CBD is much greater than the proximity to local jobs. This indicates that in an age of advanced transportation technologies, whether or not a neighborhood is located in a job-rich community is no longer a crucial factor in determining its residents' access to job opportunities, and people depend more on more distant metropolitan employment opportunities than local ones. Those findings are also consistent with the significant positive coefficient on NoCar90, which implies the importance of automobile ownership.

\section{Mobility-Related Neighborhood Attributes}

As discussed earlier, when it comes to the effect of old housing stock on neighborhood poverty status change, conflicting evidence is present in the urban literature. The results from this research indicate that a moderate-poverty neighborhood is expected to experience less poverty growth if it has a larger proportion of old housing units or a larger proportion of new housing units. So evidence is found to support Ellen and O’Regan (2007) and Rosenthal's (2007) proposal that as a neighborhood becomes older, its chance of receiving major reinvestment increases, which will elevate its economic status in the next decade. The coefficient of the variable vacancy90 


\section{H. REN, H. MORROW-JONES}

Table 1.

The descriptions of the variables.

\begin{tabular}{|c|c|c|}
\hline Variable & Description & $\begin{array}{l}\text { Expected } \\
\text { Sign }\end{array}$ \\
\hline \multicolumn{3}{|l|}{ Resident Characteristics } \\
\hline Lowedu90 & $\begin{array}{l}\text { Proportion of Residents Aged 25+ Who Complete } 0 \text { - } 8 \text { Years of School in Tract in 1990/The Counterpart in } \\
\text { MSA in } 1990\end{array}$ & + \\
\hline Foreign90 & Proportion of Foreign-Born Residents in Tract in 1990/The Counterpart in MSA in 1990 & + \\
\hline Married90 & Proportion of Married-Couple Families in Tract in 1990/The Counterpart in MSA in 1990 & - \\
\hline Female-Headed90 & Proportion of Female-Headed Families in Tract in 1990/The Counterpart in MSA in 1990 & + \\
\hline Nocar90 & Proportion of Households Without a Car in Tract in 1990/The Counterpart in MSA in 1990 & + \\
\hline \multicolumn{3}{|l|}{ Place Characteristics } \\
\hline Access-To-Local-Job90 & Job-Population Ratio in County in 1990/The Counterpart in MSA in 1990 & - \\
\hline Distance-To-CBD90 & The Tract's Distance to CBD in 1990/The Counterpart in MSA in 1990 & + \\
\hline \multicolumn{3}{|c|}{ Housing Stock Characteristics } \\
\hline ProOldHou90 & Proportion of Housing Units Aged 50+ in Tract in 1990/The Counterpart in MSA in 1990 & - \\
\hline ProNewHou90 & Proportion of Housing Units Aged 5- in Tract in 1990/The Counterpart in MSA in 1990 & - \\
\hline Vacancy90 & Housing Vacancy Rate in Tract in 1990/The Counterpart in MSA in 1990 & + \\
\hline \multicolumn{3}{|l|}{ Social Externalities } \\
\hline Poverty90 & Tract Poverty Rate in 1990/The Counterpart in MSA in 1990 & - \\
\hline Poverty80-90 & $\begin{array}{l}\text { (Tract Poverty Rate in 1990/The Counterpart in MSA in 1990) - (Tract Poverty Rate in 1980/The Counterpart } \\
\text { in MSA in 1980) }\end{array}$ & - \\
\hline Distance-To-20Pov90 & The Tract’s Distance to the Nearest Tract with 20\%+ Poverty Rate in 1990/The Counterpart in MSA in 1990 & + \\
\hline Distance-To-40Pov90 & The Tract's Distance to the Nearest Tract with 40\%+ Poverty Rate in 1990/The Counterpart in MSA in 1990 & + \\
\hline Black90 & Proportion of African-American Residents in Tract in 1990/The Counterpart in MSA in 1990 & + \\
\hline Black80-90 & $\begin{array}{l}\text { (Proportion of African-American Residents in Tract in 1990/The Counterpart in MSA in 1990) } \\
\text { - (Proportion of African-American Residents in Tract in 1980/The Counterpart in MSA in 1980) }\end{array}$ & + \\
\hline Hispanic90 & Proportion of Hispanic Residents in Tract in 1990/The Counterpart in MSA in 1990 & + \\
\hline Pop-Density90 & Tract Population Density in 1990/The Counterpart in MSA in 1990 & + \\
\hline HighIncome90 & Proportion of Families with an Annual Income \$60000+ in Tract in 1990/T he Counterpart in MSA in 1990 & - \\
\hline Highpro90 & $\begin{array}{l}\text { Proportion of Residents Aged 16+ in Executives, Managers or Administrators in Tract in 1990/The Counterpart } \\
\text { in MSA in } 1990\end{array}$ & - \\
\hline Homeowner90 & Homeownership Rate in Tract in 1990/The Counterpart in MSA in 1990 & - \\
\hline Highedu90 & Proportion of Residents Aged 25+ with a College Degree/The Counterpart in MSA in 1990 & - \\
\hline Move5years90 & $\begin{array}{l}\text { Proportion of Households Who Have Resided in the Tract for More Than } 5 \text { Years/The Counterpart in MSA } \\
\text { in } 1990\end{array}$ & - \\
\hline \multicolumn{3}{|l|}{ The Control Variable } \\
\hline Propwithchild90 ${ }^{\mathrm{a}}$ & Proportion of Families with Own Children in Tract in 1990/The Counterpart in MSA in 1990 & \\
\hline \multicolumn{3}{|l|}{ Dummy Variables } \\
\hline Poverty90-Dummy-1 & The Variable Poverty90 Exceeds One Standard Deviation Above Its Mean & - \\
\hline Poverty90-Dummy-2 & The Variable Poverty90 Exceeds Two Standard Deviation Above Its Mean & - \\
\hline Black90-Dummy-1 & The Variable Black90 Exceeds One Standard Deviation Above Its Mean & + \\
\hline Black90-Dummy-2 & The Variable Black90 Exceeds Two Standard Deviation Above Its Mean & + \\
\hline
\end{tabular}

Note: ${ }^{a}$ Families with of children are known to be more sensitive to the neighborhood environment, and therefore are expected to have a relatively higher likelihood of moving out if there's a sign of decline. So the variable "Propwithchild90" is created to control for this effect.

exhibits a significantly positive coefficient. So the expected negative effect of vacant housing units is confirmed. In moderate-poverty areas, neighborhoods with higher housing vacancy rates appear less appealing to relatively affluent households and those neighborhoods are more likely to slip into concen- trated poverty.

When it comes to social externality effects, Pop-Density90 proves to have a positive impact on poverty rate increase. So neighborhoods with relatively higher population density are in a disadvantaged position in the competition for more affluent 


\section{H. REN, H. MORROW-JONES}

Table 2.

Results of moderate poverty tracts.

\begin{tabular}{|c|c|c|c|}
\hline \multicolumn{4}{|c|}{ (Adjusted R-squared = 0.202; $\mathrm{N}=7814$ ) } \\
\hline Explanatory Variables & Coefficient & Std-Error & T-value \\
\hline Constant & 0.0179 & 0.0144 & 1.2444 \\
\hline \multicolumn{4}{|l|}{ Resident Characteristics } \\
\hline Lowedu90 & $0.0699^{* * *}$ & 0.0154 & 4.5498 \\
\hline Foreign90 & $0.0951^{* * *}$ & 0.0130 & 7.3233 \\
\hline Married90 & $-0.0628^{* * *}$ & 0.0197 & -3.1898 \\
\hline Female-Headed90 & $0.0728^{* * *}$ & 0.0211 & 3.4515 \\
\hline Nocar90 & $0.1092^{* * *}$ & 0.0144 & 7.5605 \\
\hline \multicolumn{4}{|l|}{ Place Characteristics } \\
\hline Access-To-Local-Job90 & $-0.0385^{* * *}$ & 0.0113 & -3.4109 \\
\hline \multicolumn{4}{|c|}{ Housing Stock Characteristics } \\
\hline ProOldHou90 & $-0.0465^{* * *}$ & 0.0117 & -3.9688 \\
\hline ProNewHou90 & $-0.0559^{* * *}$ & 0.0119 & -4.6846 \\
\hline Vacancy90 & $0.0644^{* * *}$ & 0.0114 & 5.6677 \\
\hline \multicolumn{4}{|l|}{ Social Externalities } \\
\hline Poverty90 & $-0.2262^{* * *}$ & 0.0172 & -13.1856 \\
\hline Poverty80-90 & $-0.0749^{* * * *}$ & 0.0116 & -6.4587 \\
\hline Distance-To-20Pov90 & $-0.0897^{* * *}$ & 0.0155 & -5.7894 \\
\hline Distance-To-40Pov90 & $-0.0898^{* * *}$ & 0.0201 & -4.4730 \\
\hline Black90 & $0.1376^{* * *}$ & 0.0218 & 6.3235 \\
\hline Black80-90 & $0.0693^{* * *}$ & 0.0112 & 6.1720 \\
\hline Pop-Density90 & $0.0748^{* * *}$ & 0.0107 & 6.9659 \\
\hline HighIncome90 & $-0.031^{*}$ & 0.0168 & -1.8439 \\
\hline Highpro90 & $-0.0697^{* * *}$ & 0.0153 & -4.5482 \\
\hline Homeowner90 & $-0.0969^{* * *}$ & 0.0168 & -5.7823 \\
\hline Highedu90 & $-0.1071^{* * *}$ & 0.0212 & -5.0617 \\
\hline Move5years90 & $-0.0515^{* * *}$ & 0.0168 & -3.0657 \\
\hline \multicolumn{4}{|l|}{ The Control Variable } \\
\hline Propwithchild90 & 0.0114 & 0.0150 & 0.7599 \\
\hline \multicolumn{4}{|l|}{ Dummy Variables } \\
\hline Poverty90-Dummy-1 & -0.0132 & 0.039 & -0.3383 \\
\hline Poverty90-Dummy-2 & -0.1257 & 0.0774 & -1.6251 \\
\hline Black90-Dummy-1 & -0.0439 & 0.054 & -0.8133 \\
\hline Black90-Dummy-2 & $-0.166^{* *}$ & 0.0732 & -2.2698 \\
\hline
\end{tabular}

Note: All estimates are produced by SPSS 13 , using standardized scores. ${ }^{*} P<0.1,{ }^{* *} P<0.05,{ }^{* * *} P<0.01$.

residents. Following Rosenthal's approach (2007), we use density as an indirect measure for the level of criminal activities. Density can also serve as a proxy for many other povertyrelated factors. For example, while higher-density neighborhoods are expected to frighten away wealthier families because of their perceived higher crime rates, it is also plausible that people might be actually deterred by the higher tax rates, and poorer quality schools of central city communities since higherdensity neighborhoods are more likely to be located in central city areas. With limited data sources, it is not possible to differentiate between these possible poverty-generating mechanisms.

On the social capital side, all four variables exhibit significantly negative coefficients as expected. Neighborhoods with 
relatively higher proportions of high-income families, college graduates and residents with high-status jobs, have an advantaged competitive position in the metropolitan area, and therefore are likely to experience less poverty growth. The social capital created by these variables makes a neighborhood more appealing and works as an attractor for affluent families. On the other hand, they are also supposed to help the incumbent neighborhood residents thrive by providing positive role models and increasing social interaction in the community (Rosenthal, 2007; Ellen \& O’Regan, 2007). As the most prominent social capital generator as proved by numerous past studies (Brueckner, 1977; Carter et al., 1998; Galster et al., 2003; Ellen \& O’Regan, 2007; Rosenthal, 2007), homeownership's role in resisting poverty growth is confirmed in this study. The variable Move5Years90 represents the proportion of the households who have resided in the neighborhood for more than 5 years. The significantly negative sign of this variable supports the view that neighborhood stability helps to resist future poverty growth.

The analysis results report a positive correlation between the relative proportion of African Americans and future neighborhood poverty growth. The past racial transition trend (Black8090) proves to be influential as well. Those findings indicate that relatively high percentages of African-American residents are still associated with declines in moderate-poverty urban areas where there is often a relatively large white population. The findings provide support for Ellen's (2000) "race-based neighborhood stereotyping hypothesis" that although pure racial prejudice has lost its popularity, white people still tend to use race as a measure to estimate future neighborhood quality when making residential location decisions.

The model results also show that once the relative proportion of African-American residents exceeds two standard deviations above the mean, the negative effect of Black90 is significantly muted. This result confirms the other side of racial effects. That is, once the percentage of minority residents surpasses certain thresholds the large share of minorities becomes a neighborhood stabilizer. This supports the idea that African Americans can take advantage of race-based support networks to cope with economic hardship (Galster \& Mincy, 1993). The relative proportion of Hispanic residents is irrelevant to future poverty growth in moderate-poverty neighborhoods.

Four variables are created to examine the endogenous effects of concentrated poverty. Similar to racial variables, Poverty90 and Poverty80-90 are used to test the effects of income tipping and the past trend of income transition. Distance-To-20Pov90 and Distance-To-40Pov90 are used to evaluate the spill-over or border effects of concentrated poverty.

Some interesting results are found. Consistent with conventional wisdom, the two distance variables have negative coefficients which mean that proximity to concentrated poverty contributes to future poverty increase. However, the signs for the coefficients of both Poverty90 and Poverty80-90 are significantly negative. These results suggest that a neighborhood will go through more poverty growth if it is located closer to other neighborhoods with high poverty rates, but it will experience less poverty growth if it has a relatively higher poverty status itself.

It seems unreasonable that affluent households would be attracted to neighborhoods with relatively higher poverty status, while in the meantime trying to avoid those with proximity to concentrated poverty. One explanation is that strong policy intervention has been involved in the neighborhood poverty transition process during the 1990s. As Ellen and O'Regan (2007) suggest, numerous anti-poverty initiatives were put into practice during this period. These include strict enforcement of anti-discrimination laws in housing markets, welfare reforms, and other programs designed to promote employment rates among the working poor. With those anti-poverty efforts, the presence of a higher proportion of poor individuals actually increases a neighborhood's chance of receiving government assistance and therefore makes it less likely to experience poverty growth in the subsequent decade. The two distance variables mainly reflect the effects of natural economic forces.

In summary, our quantitative model works well to explain the course of poverty transition of moderate-poverty neighborhoods in US metropolitan areas. In general, neighborhoods with attributes that gives them advantages in the inter-neighborhood competition, show better ability to resist future poverty increase. These attributes include a relatively larger proportion of married couple families, a relatively larger proportion of homeowners, and so on. On the other hand, neighborhoods with attributes that gives them disadvantages in the inter-neighborhood competition, are more subject to future poverty growth. These attributes include a relatively higher density, relatively larger African American population and so on.

\section{Conclusions, Discussion and Future Research Directions}

\section{Conclusions and Policy Implications}

Concentrated poverty has long been a focus in the urban literature, but most of the previous studies focus on areas that already have high concentrations of poverty in the hope of helping these distressed urban areas get out of impoverished conditions. This study is intended to complement the urban poverty literature by discovering poverty dynamics patterns in moderately poor urban areas, so that policies can be made to intervene in the process by which poverty gets concentrated. A competitive model is established to explore the course of neighborhood poverty concentration. Several important findings are revealed and they lead to interesting policy recommendations.

Most of anti-poverty programs are reactive rather than preventive in nature. That is, they tend to target already poor urban neighborhoods in the hope of poverty deconcentration instead of working on moderately poor areas to impede the downward filtering process. Some urban programs apply a place-oriented approach, such as the empowerment zone (EZ) which offers tax breaks and other policy benefits to attract business investments to upgrade distressed areas. Some programs rely on a peopleoriented perspective and aim to fight concentrated poverty by helping poor individuals directly, such as community training programs and the moving to opportunity (MTO) program (Temkin \& Rohe, 1996). All these programs underplayed the fact that the best way to fight concentrated poverty is to prevent poverty from getting concentrated. The policy emphasis, therefore, should be shifted towards these areas where noticeable amount of poverty is present but the magnitude is not significant enough to cause substantial socials problems and subsequent income tipping.

The important finding of the competitive model applied in this study is that neighborhood poverty status is a dynamic process instead of a static phenomenon. As a result of intensive inter-neighborhood competitions, those with unfavorable posi- 
tions will keep declining, eventually leading to concentrated poverty and a stratified metropolis pattern. Also, when it comes to poverty rate transition due to people's mobility patterns, some neighborhoods' gains of affluent households are others' losses. From a local perspective, some communities may become the winners of the competition and experience growth in economic status, but for the region as a whole, it is a zero-sum game at best (Orfield, 2002). Therefore, to prevent the stratification of metropolitan patterns and wasteful competition, a regional perspective is needed when enacting and implementing public policies, and some type of governing body at the metropolitan level is required to coordinate local efforts.

The findings of this research also provide a rich set of empirical results needed for enacting specific policies. For example, those areas with a large body of residents in disadvantaged competitive positions should be given more attention by policy makers, such as neighborhoods with a higher percentage of female-headed families or a higher percentage of new immigrants. Automobile ownership is another significant factor in explaining neighborhood poverty growth, indicating the importance of transportation means for gaining access to job opportunities. A well-developed public transit system might fill this vacancy and therefore increase an area's ability to resist poverty growth.

Evidence to support central-city revitalization programs is found in this study also. Although decentralization has become the dominant pattern of economic activities, people living in moderately poor urban areas still have heavy reliance on CBD jobs. This finding also conforms to what observed by Downs (1994) who contends that central cities are still desirable locations for a wide variety of industries.

\section{Future Research Directions}

This study contributes to the urban poverty literature by exploring the poverty succession mechanisms in moderate-poverty neighborhoods. From a practical perspective, a set of poverty change predictors are identified, which can serve as the basis for formulating anti-poverty policies targeting particularly moderately poor neighborhoods to prevent them from degrading into high-poverty areas. From a theoretical perspective, this study enriches the existing urban poverty literature with its model of explaining neighborhood poverty dynamics through the inter-neighborhood competition.

It should be noted that this study is an initial step in modeling neighborhood poverty change from an inter-neighborhoodcompetition perspective. There are several important limitations that we hope can be overcome by future research.

To begin with, a richer set of explanatory variables might help to improve the model. For example, many possible povertychange indicators are not available in NCDB and REIS, the two major datasets used in this study. We have no direct measure for school quality which is probably the most important factor to consider when a family makes residential choices. Also, the explanatory power of the model might be significantly expanded if influential factors at larger geographical scale could be added, such as metropolitan demographic changes and largerscale economic dynamics.

In addition, we carefully selected explanatory variables in order to separate the effects of the two poverty-generating mechanisms: incumbent income changes and selective migration. The results were unexpected in that most neighborhood-level variables affect poverty transition through both of the two processes. For example, a higher proportion of college graduates generates higher levels of social capital and therefore elevates the economic status of the neighborhood by attracting more affluent families. On the other hand, these highly-educated people themselves are in a favorable position in employment markets and can also help the rest of the neighborhood residents prosper through positive role-model effects. A single city or single metro case study with more detailed information will work better to distinguish between the effects of these two mechanisms.

Finally, we relied solely on the traditional OLS method to perform statistical analyses. The accuracy of the results will certainly be improved if more sophisticated statistical approaches can be employed, such as using spatial regression models to take care of spatial autocorrelation and applying simultaneous equation modeling to explore complex interactions of different neighborhood attributes.

The primary purpose of this study is to provide a new framework for understanding the dynamics of moderately poor urban areas and to perform a first test of its usefulness. As more elements are added by future research, especially with the newly-released Census 2010 data, we hope the model proposed in this study will give us a deeper insight into the neighborhood transition mechanisms.

\section{REFERENCES}

Brueckner, J. (1977). The determinants of residential succession. Journal of Urban Economics, 4, 45-59. http://dx.doi.org/10.1016/0094-1190(77)90029-8

Carter, W. H., Schill, M. H., \& Wachter, S. M. (1998). Polarisation, public housing and racial minorities in US cities. Urban Studies, 35, 1889-1911. http://dx.doi.org/10.1080/0042098984204

Cohen, C. J., \& Dawson, M. C. (1993). Neighborhood poverty and African American politics. American Political Science Review, 87, 286-302. http://dx.doi.org/10.2307/2939041

DiPasquale, D., \& Glaeser, E. L. (1999). Incentives and social capital: Are homeowners better citizens? Journal of Urban Economics, 45, 354-384. http://dx.doi.org/10.1006/juec.1998.2098

Downs, A. (1994). New vision for metropolis America: Why we need a new vision. Washington, DC: Brookings Institution.

Eggers, M. L., \& Massey, D. S. (1992). A longitudinal analysis of urban poverty: Blacks in U.S. metropolitan areas between 1970 and 1980. Social Science Research, 21, 175-203. http://dx.doi.org/10.1016/0049-089X(92)90014-8

Ellen, I. G. (2000). Sharing America's neighborhoods: The prospects for stable, racial integration. Cambridge, MA: Harvard University Press.

Ellen, I. G., \& O’Regan, K. (2007). Reversal of fortunes? Lowerincome urban neighborhoods in the US in the 1990s. Urban Studies, 45, 845-869.

Fogarty, M. S. (1977). Predicting neighborhood decline within a large central city: An application of discriminant analysis. Environment and Planning A, 9, 579-584. http://dx.doi.org/10.1068/a090579

Galster, G. C. (2001). On the nature of neighborhood. Urban Studies, 38, 2111-2124. http://dx.doi.org/10.1080/00420980120087072

Galster, G. C., Quercia, R. G., Cortes, A., \& Malega, R. (2003). The Fortunes of poor neighborhoods. Urban Affairs Review, 39, 205-227. http://dx.doi.org/10.1177/1078087403254493

Hughes, M. (1989). Mispeaking truth to power: A geographical perspective on the "underclass” fallacy. Economic Geography, 65, 187207. http://dx.doi.org/10.2307/143834

Jargowsky, P. (1997). Poverty and place: Ghettos, barrios, and the American city. New York: Russell Sage Foundation.

Jargowsky, P. (2003). Stunning progress, hidden problems: The dra- 


\section{H. REN, H. MORROW-JONES}

matic decline of concentrated poverty in the 1990s. Washington, DC: Brookings Institution Press.

Jargowsky, P., \& Bane, M. J. (1990). GHETTO poverty: Basic questions. In Inner-city poverty in the United States. Washington, DC: National Academy Press.

Kasarda, J. (1993). Inner-city concentrated poverty and neighborhood distress: 1970 to 1990. Housing Policy Debate, 4, 253-302. http://dx.doi.org/10.1080/10511482.1993.9521135

Kingsley, G. T., \& Pettit, K. (2003). Concentrated poverty: A change in course. Washington, DC: The Urban Institute.

Leven, C., Little, J., Nourse, H., \& Read, R. (1976). Neighborhood change: Lessons in the dynamics of urban decay. New York: Praeger Publishers.

Massey, D. S., \& Eggers, M. L. (1990). The ecology of inequality: Minorities and the concentration of poverty, 1970-1980. American Journal of Sociology, 95, 1153-1188. http://dx.doi.org/10.1086/229425

Massey, D., Eggers, M., \& Denton, N. (1990). Disentangling the causes of concentrated poverty. Unpublished Paper, Chicago, IL: Population Research Center, NORC/University of Chicago.

Metzger, J. (2000). Planned abandonment: The neighborhood life-cycle theory and national urban policy. Housing Policy Debate, 11, 7-40. http://dx.doi.org/10.1080/10511482.2000.9521359

Mincy, R. B., Sawhill, I., \& Wolf, D. (1990). The underclass: Definition and measurement. Science, 248, 450-453. http://dx.doi.org/10.1126/science.248.4954.450

Oreopoulos, P. (2003). The long-run consequences of growing up in a poor neighborhood. Quarterly Journal of Economics, 118, 15331575. http://dx.doi.org/10.1162/003355303322552865

Orfield, M., \& Katz, B. (2002). American metropolitics: The new suburban reality. Washington, DC: Brookings Institution Press.

Quercia, R. G., \& Galster, G. C. (2000). Thresh-old effects and neighborhood change, Journal of Planning Education and Research, 20, 146-162. http://dx.doi.org/10.1177/0739456X0002000202

Rosenthal, S. (2007). Old homes, externalities, and poor neighborhoods: A model of urban decline and renewal. Journal of Urban Economics, 63, 816-840. http://dx.doi.org/10.1016/j.jue.2007.06.003

Schuler, J., Kent, R., \& Monroe, B. (1992). Neighborhood gentrification: A discriminant analysis of a historic district in Cleveland, Ohio. Urban Geography, 13, 49-67. http://dx.doi.org/10.2747/0272-3638.13.1.49

Scott, A. (1988). Metropolis: From division of labor to urban form. Berkeley, CA: University of California Press.

Tatian, A. P. (2003). Neighborhood change database: Data users' guide. http://www.geolytics.com/pdf/NCDB-LF-Data-Users-Guide.pdf

Temkin, K., \& Robe, W. (1996). Neighborhood change and urban policy. Journal of Planning Education and Research, 15, 159-170. http://dx.doi.org/10.1177/0739456X9601500301

Wilson, W. J. (1987). The truly disadvantaged. Chicago, IL: The University of Chicago Press. 


\section{H. REN, H. MORROW-JONES}

\section{Appendix}

Table A.

The 100 largest MSAs.

\begin{tabular}{|c|c|c|c|}
\hline Rank & MSA Name & Population (1990) & Population (2000) \\
\hline 1 & Los Angeles-Long Beach-Santa Ana, CA & $8,803,804$ & $9,463,883$ \\
\hline 2 & New York-Northern New Jersey-Long Island, NY-NJ-PA & $8,485,881$ & $9,261,473$ \\
\hline 3 & Chicago-Joliet-Naperville, IL-IN-WI & $7,263,100$ & $8,107,644$ \\
\hline 4 & Philadelphia-Camden-Wilmington, PA-NJ-DE-MD & $4,853,879$ & $5,037,277$ \\
\hline 5 & Detroit-Warren-Livonia, MI & $4,256,681$ & $4,429,015$ \\
\hline 6 & Washington-Arlington-Alexandria, DC-VA-MD-WV & $3,915,023$ & $4,537,017$ \\
\hline 7 & Houston-Sugar Land-Baytown, TX & $3,317,651$ & $4,162,976$ \\
\hline 8 & Boston-Cambridge-Quincy, MA-NH & $3,163,429$ & $3,349,729$ \\
\hline 9 & Atlanta-Sandy Springs-Marietta, GA & $2,659,377$ & $3,712,871$ \\
\hline 10 & Nassau-Suffolk, NY PMSA & $2,588,748$ & $2,740,474$ \\
\hline 11 & Riverside-San Bernardino-Ontario, CA & $2,553,696$ & $3,216,638$ \\
\hline 12 & Dallas-Fort Worth-Arlington, TX & $2,539,540$ & $3,312,284$ \\
\hline 13 & Minneapolis-St. Paul-Bloomington, MN-WI & $2,470,395$ & $2,888,515$ \\
\hline 14 & St. Louis, MO-IL & $2,465,930$ & $2,575,551$ \\
\hline 15 & San Diego-Carlsbad-San Marcos, CA & $2,411,260$ & $2,682,438$ \\
\hline 16 & Orange County, CA PMSA & $2,406,318$ & $2,772,046$ \\
\hline 17 & Baltimore-Towson, MD & $2,317,207$ & $2,478,515$ \\
\hline 18 & Pittsburgh, PA & $2,229,272$ & $2,190,442$ \\
\hline 19 & Phoenix-Mesa-Glendale, AZ & $2,224,932$ & $3,114,937$ \\
\hline 20 & Cleveland-Elyria-Mentor, $\mathrm{OH}$ & $2,190,554$ & $2,235,084$ \\
\hline 21 & San Francisco-Oakland-Fremont, CA & $2,061,150$ & $2,377,318$ \\
\hline 22 & Seattle-Tacoma-Bellevue, WA & $1,967,708$ & $2,340,497$ \\
\hline 23 & Tampa-St. Petersburg-Clearwater, FL & $1,963,580$ & 2,248,952 \\
\hline 24 & Miami-Fort Lauderdale-Pompano Beach, FL & $1,932,629$ & $2,228,236$ \\
\hline 25 & Newark, NJ PMSA & $1,892,972$ & $2,009,948$ \\
\hline 26 & Denver-Aurora-Broomfield, CO & $1,614,261$ & $2,073,249$ \\
\hline 27 & San Francisco-Oakland-Fremont, CA & $1,601,830$ & $1,729,392$ \\
\hline 28 & Kansas City, MO-KS & $1,509,671$ & $1,689,903$ \\
\hline 29 & San Jose-Sunnyvale-Santa Clara, CA & $1,486,159$ & $1,670,333$ \\
\hline 30 & Portland-Vancouver-Hillsboro, OR-WA & $1,477,750$ & $1,874,313$ \\
\hline 31 & Cincinnati-Middletown, OH-KY-IN & $1,449,682$ & $1,555,636$ \\
\hline 32 & Milwaukee-Waukesha-West Allis, WI & $1,424,494$ & $1,493,311$ \\
\hline 33 & Virginia Beach-Norfolk-Newport News, VA-NC & $1,376,102$ & $1,521,625$ \\
\hline 34 & Indianapolis-Carmel, IN & $1,374,677$ & $1,603,105$ \\
\hline 35 & Fort Worth-Arlington, TX PMSA & $1,353,764$ & $1,691,352$ \\
\hline 36 & Columbus, $\mathrm{OH}$ & $1,334,674$ & $1,523,881$ \\
\hline 37 & Sacramento-Arden-Arcade-Roseville, CA & $1,333,407$ & $1,540,760$ \\
\hline 38 & San Antonio-New Braunfels, TX & $1,287,621$ & $1,541,284$ \\
\hline 39 & Bergen-Passaic, NJ PMSA & $1,277,980$ & $1,372,791$ \\
\hline 40 & Fort Lauderdale-Hollywood-Pompano Beach, FL PMSA & $1,255,242$ & $1,530,737$ \\
\hline 41 & New Orleans-Metairie-Kenner, LA & $1,214,326$ & $1,266,582$ \\
\hline 42 & Orlando-Kissimmee-Sanford, FL & $1,213,005$ & $1,632,377$ \\
\hline 43 & Buffalo-Niagara Falls, NY & $1,178,011$ & $1,161,926$ \\
\hline 44 & Hartford-West Hartford-East Hartford, CT & $1,133,991$ & $1,167,171$ \\
\hline 45 & Providence-New Bedford-Fall River, RI-MA & $1,116,411$ & $1,170,823$ \\
\hline 46 & Charlotte-Gastonia-Rock Hill, NC-SC & $1,109,365$ & $1,433,620$ \\
\hline
\end{tabular}




\section{H. REN, H. MORROW-JONES}

Continued

\begin{tabular}{|c|c|c|c|}
\hline 47 & Salt Lake City, UT & $1,070,600$ & $1,326,965$ \\
\hline 48 & Greensboro-High Point, NC & $1,006,213$ & $1,200,117$ \\
\hline 49 & Middlesex-Somerset-Hunterdon, NJ PMSA & 985,716 & $1,139,643$ \\
\hline 50 & Rochester, NY & 985,477 & $1,023,027$ \\
\hline 51 & Memphis, TN-MS-AR & 985,090 & $1,122,347$ \\
\hline 52 & Monmouth-Ocean, NJ PMSA & 983,890 & $1,125,219$ \\
\hline 53 & Nashville-Davidson-Murfreesboro-Franklin, TN & 971,835 & $1,218,485$ \\
\hline 54 & Dayton, $\mathrm{OH}$ & 947,571 & 946,566 \\
\hline 55 & Grand Rapids-Wyoming, MI & 937,836 & $1,088,426$ \\
\hline 56 & Oklahoma City, OK & 922,673 & $1,040,958$ \\
\hline 57 & Louisville-Jefferson County, KY-IN & 895,404 & 966,034 \\
\hline 58 & Jacksonville, FL & 894,351 & $1,094,171$ \\
\hline 59 & West Palm Beach, FL SMSA & 860,943 & $1,127,640$ \\
\hline 60 & Richmond, VA & 850,439 & 978,327 \\
\hline 61 & Birmingham-Hoover, AL & 840,139 & 921,106 \\
\hline 62 & Honolulu, HI & 818,435 & 831,910 \\
\hline 63 & Albany-Schenectady-Troy, NY & 812,897 & 828,822 \\
\hline 64 & Raleigh-Cary, NC & 790,272 & $1,110,405$ \\
\hline 65 & Greenville-Mauldin-Easley, SC & 774,278 & 899,596 \\
\hline 66 & Austin-Round Rock-San Marcos, TX & 763,024 & $1,142,566$ \\
\hline 67 & Fresno, CA & 754,474 & 917,162 \\
\hline 68 & Las Vegas-Paradise, NV & 740,120 & $1,121,269$ \\
\hline 69 & Tulsa, OK & 704,606 & 796,096 \\
\hline 70 & Oxnard-Thousand Oaks-Ventura, CA & 661,917 & 746,186 \\
\hline 71 & Tucson, AZ & 658,178 & 832,275 \\
\hline 72 & Syracuse, NY & 637,106 & 631,198 \\
\hline 73 & Akron, $\mathrm{OH}$ & 633,030 & 670,905 \\
\hline 74 & Omaha-Council Bluffs, NE-IA & 614,525 & 672,601 \\
\hline 75 & Toledo, $\mathrm{OH}$ & 603,579 & 608,454 \\
\hline 76 & Gary, IN PMSA & 599,556 & 626,703 \\
\hline 77 & Allentown-Bethlehem-Easton, PA-NJ & 592,210 & 636,936 \\
\hline 78 & El Paso, TX & 591,248 & 673,263 \\
\hline 79 & Harrisburg-Carlisle, PA & 587,987 & 629,401 \\
\hline 80 & Seattle-Tacoma-Bellevue, WA & 579,782 & 693,485 \\
\hline 81 & Springfield, MA & 568,257 & 571,903 \\
\hline 82 & Jersey City, NJ SMSA & 552,992 & 608,811 \\
\hline 83 & Scranton-Wilkes-Barre, PA & 547,267 & 532,545 \\
\hline 84 & Albuquerque, NM & 541,723 & 637,528 \\
\hline 85 & Bakersfield-Delano, CA & 537,646 & 644,418 \\
\hline 86 & New Haven-Milford, CT & 524,742 & 535,921 \\
\hline 87 & Baton Rouge, LA & 517,085 & 590,591 \\
\hline 88 & Wilmington, NC & 508,170 & 579,329 \\
\hline 89 & Knoxville, TN & 496,577 & 569,133 \\
\hline 90 & Charleston, WV & 494,596 & 543,387 \\
\hline 91 & Youngstown-Warren-Boardman, OH-PA & 492,699 & 482,671 \\
\hline 92 & North Port-Bradenton-Sarasota, FL & 489,487 & 583,940 \\
\hline 93 & Wichita, KS & 485,269 & 545,220 \\
\hline 94 & Stockton, CA & 473,856 & 547,774 \\
\hline 95 & Worcester, MA & 471,667 & 504,396 \\
\hline 96 & Mobile, AL & 469,485 & 533,071 \\
\hline
\end{tabular}




\section{H. REN, H. MORROW-JONES}

Continued

\begin{tabular}{cllc}
\hline 97 & Little Rock-North Little Rock-Conway, AR & 451,305 & 496,830 \\
98 & Bridgeport-Stamford-Norwalk, CT & 441,589 \\
99 & Vallejo-Fairfield, CA & 434,757 & 457,968 \\
100 & Johnson City, TN & 433,915 & 478,035 \\
\hline
\end{tabular}

Source: The Bureau of Economic Analysis’ Regional Information System (REIS).

Table B.

Descriptive statistics for different poverty-level tracts.

\begin{tabular}{|c|c|c|c|c|c|c|c|c|c|}
\hline \multirow[t]{3}{*}{ Dependent Variable } & & & & & & & & & \\
\hline & \multicolumn{3}{|c|}{ Mod-Poverty Tracts } & \multicolumn{3}{|c|}{ High-Poverty Tracts } & \multicolumn{3}{|c|}{ Ex-Poverty Tracts } \\
\hline & $\mathbf{N}$ & Mean & STD & $\mathbf{N}$ & Mean & STD & $\mathbf{N}$ & Mean & STD \\
\hline Povratechange90-00 & 7814 & 0.0106 & 0.0599 & 5221 & -0.0064 & 0.0797 & 1946 & -0.0896 & 0.1133 \\
\hline \multicolumn{10}{|l|}{ Resident Characteristics } \\
\hline Lowedu90 & 7814 & 0.1182 & 0.0758 & 5221 & 0.1973 & 0.1167 & 1946 & 0.2270 & 0.1152 \\
\hline Foreign90 & 7814 & 0.1320 & 0.1515 & 5221 & 0.1695 & 0.1901 & 1946 & 0.1008 & 0.1445 \\
\hline Married90 & 7814 & 0.7322 & 0.1003 & 5221 & 0.5858 & 0.1385 & 1946 & 0.3905 & 0.1708 \\
\hline Female-Headed90 & 7814 & 0.1365 & 0.0651 & 5221 & 0.2355 & 0.1023 & 1946 & 0.3892 & 0.1494 \\
\hline Nocar90 & 7814 & 0.1562 & 0.1422 & 5221 & 0.2987 & 0.1866 & 1946 & 0.5258 & 0.2056 \\
\hline \multicolumn{10}{|l|}{ Place Characteristics } \\
\hline Distance-To-CBD90 & 7814 & 14.7510 & 14.2428 & 5221 & 10.1450 & 12.4403 & 1946 & 6.0768 & 7.6611 \\
\hline \multicolumn{10}{|c|}{ Housing Stock Characteristics } \\
\hline ProOldHou90 & 7814 & 0.2314 & 0.2527 & 5221 & 0.3150 & 0.2553 & 1946 & 0.3457 & 0.2270 \\
\hline ProNewHou90 & 7814 & 0.0821 & 0.1035 & 5221 & 0.0546 & 0.0778 & 1946 & 0.0376 & 0.0605 \\
\hline Vacancy90 & 7814 & 0.0841 & 0.0665 & 5221 & 0.1071 & 0.0674 & 1946 & 0.1408 & 0.0954 \\
\hline \multicolumn{10}{|l|}{ Social Externalities } \\
\hline Poverty90 & 7814 & 0.1416 & 0.0286 & 5221 & 0.2822 & 0.0567 & 1946 & 0.5119 & 0.1039 \\
\hline Poverty80-90 & 7814 & 0.0197 & 0.0530 & 5221 & 0.0480 & 0.0846 & 1946 & 0.1033 & 0.1112 \\
\hline Distance-To-20Pov90 & 7814 & 4.0659 & 6.7175 & 5221 & & & 1946 & & \\
\hline Distance-To-40Pov90 & 7814 & 10.3539 & 14.6089 & 5221 & 5.4683 & 12.3336 & 1946 & & \\
\hline Black90 & 7814 & 0.1578 & 0.2440 & 5221 & 0.3584 & 0.3521 & 1946 & 0.5988 & 0.3616 \\
\hline Hispanic90 & 7814 & 0.1460 & 0.1911 & 5221 & 0.2438 & 0.2859 & 1946 & 0.2042 & 0.2870 \\
\hline Pop-Density90 & 7814 & 9406 & 15514 & 5221 & 14255 & 20921 & 1946 & 16568 & 23519 \\
\hline HighIncome90 & 7814 & 0.1506 & 0.0994 & 5221 & 0.0820 & 0.0690 & 1946 & 0.0353 & 0.0519 \\
\hline Highpro90 & 7814 & 0.1034 & 0.0427 & 5221 & 0.0746 & 0.0399 & 1946 & 0.0553 & 0.0390 \\
\hline Homeowner90 & 7814 & 0.5350 & 0.2128 & 5221 & 0.3974 & 0.2119 & 1946 & 0.2519 & 0.1882 \\
\hline Highedu90 & 7814 & 0.1666 & 0.1263 & 5221 & 0.1132 & 0.1089 & 1946 & 0.0684 & 0.0883 \\
\hline Move5years90 & 7814 & 0.4834 & 0.1446 & 5221 & 0.4840 & 0.1489 & 1946 & 0.4873 & 0.1468 \\
\hline \multicolumn{10}{|l|}{ The Control Variable } \\
\hline Propwithchild90 & 7814 & 0.4951 & 0.1023 & 5221 & 0.5546 & 0.1052 & 1946 & 0.6118 & 0.1265 \\
\hline
\end{tabular}

Note: All entries are based on the original data, as opposed to the relative measures used in the quantitative models. 